\title{
Effect of a 4-week detraining period followed by a 4-week strength program on isokinetic strength in elite youth soccer players
}

\author{
Samolis Vassilis ${ }^{1}$, Michailidis Yiannis ${ }^{1},{ }^{*}$, Mandroukas Athanasios ${ }^{2}$, Mikikis Dimitrios ${ }^{1}$, Gissis loannis ${ }^{3}$, Metaxas Thomas ${ }^{1}$ \\ 'Laboratory of Evaluation of Human Biological Performance, Department of Physical Education and Sports Sciences, Aristotle University of Thessaloniki, Thessaloniki, \\ Greece \\ ${ }^{2}$ Faculty of Physical Education and Sport, Charles University, Prague, Czech Republic \\ ${ }^{3}$ Department of Physical Education and Sports Sciences, Aristotle University of Thessaloniki, Serres, Greece
}

The aim of the present study was to determine if 4 weeks of training cessation (detraining) followed by a 4-week strength training program can affect the isokinetic strength of elite youth soccer players. There were 13 players who participated in the study. The players performed anthropometric measurements and lower limb isokinetic strength measurements 3 times, before the training cessation, after the training cessation and after the 4-week strength training program. No significant differences were observed in the anthropometric and strength measurements $(P>0.05)$ after the detraining period and after the training program $(P>0.05)$. These results indicate that 4 weeks of detraining in elite youth soccer players does not have any significant effects according to their anthropometric characteristics and isokinetic strength of their lower limbs. Furthermore, neither the 4-week training program affected the parameters above. Perhaps, youth players can maintain the benefits of training better than adults due to their neural adaptations. The duration of the strength training program could be the reason of the lack of adaptations.

Keywords: Youth soccer players, Detraining, Strength program

\section{INTRODUCTION}

The soccer season is most commonly divided into three segments: (a) the preseason period, (b) the competitive period, and (c) the off season period. The point of the preseason period is to increase individual and team performance as far as the fitness, technical and tactical aspects are concerned. In the competitive period the purpose of coaches is to improve even more the above factors and to stabilize the teams' performance for almost a ten month period. Off season period is very useful for players' psychological, mental and physical regeneration and is also useful for individual improvements and to rebuild for the following season. The duration of preseason and competition period is 10 to 11 months (Reilly and Ekblom, 2005) and the duration of off-season period is almost 6 weeks.
The off-season period usually lasts from 4 to 6 weeks and is characterized by pause of training or reduction in the volume, intensity and frequency of training (Mujika and Padilla, 2000a, 2000b). This period, most of the times is divided in to two periods: the recovery period where the players do not participate in any kind of training and the maintain period where the players have to retain their performance until the beginning of the preparation period. However, all of the above changes in the training characteristics (volume, intensity, frequency) can lead to fitness detraining. Detraining could be defined as "the partial or complete loss of training induced anatomical, physiological and performance adaptations, as a consequence of training reduction or cessation" (Mujika and Padilla, 2000a). One fitness factor that is affected by detraining is strength. Research findings in youth indicate that detraining results are complex. More specific some
${ }^{*}$ Corresponding author: Michailidis Yiannis (iD https://orcid.org/0000-0002-9738-7373 Department of Physical Education and Sports Sciences, Aristotle University of Thessaloniki, New Buildings of Laboratories, P.O. 57001, University Campus of Thermi, Thessaloniki, Greece

E-mail: ioannimd@phed.auth.gr

Received: October 26, 2018 / Accepted: January 6, 2019
This is an Open Access article distributed under the terms of the Creative Commons Attribution Non-Commercial License (http://creativecommons.org/licenses/by-nc/4.0/) which permits unrestricted non-commercial use, distribution, and reproduction in any medium, provided the original work is properly cited. 
studies mentioned that the power decreased in the duration of the detraining period (Faigenbaum et al., 2013; Fathi et al., 2018) and in others that power remains stable in the detraining period (Santos et al., 2011; Santos et al., 2012). In addition, the strength that was gained after training, decreased in the duration of the detraining period (Chaouachi et al., 2018; Chatzinikolaou et al., 2018; Ingle et al., 2006; Meylan et al., 2014).

However, the off season period is very useful for players and coaches to recover and to "prepare" for the following season (Silva et al., 2016). More precisely can improve their individual technical and tactical performance and their physical condition. This period is vital for these improvements because the team did not have competitive matches.

The study of the effects of detraining on physical condition abilities began 40 years ago (Staron et al., 1981; Thorstensson, 1977). However, all these years the researchers paid more attention to the effects of detraining on the athlete's endurance and the number of studies that have focused on strength detraining are fewer. Additionally, most of the studies were performed by adults and only in a small number of studies youths participated. From what we know, there is a small number of studies that focuses on the effects of detraining on the physical condition of elite youth soccer players. The training period for youth soccer is approximately 10 months and they have 2 months for recovery/holi-

Table 1. Training program characteristics

\begin{tabular}{|c|c|c|c|c|c|}
\hline \multirow{2}{*}{ Session } & \multirow{2}{*}{ Exercises } & \multicolumn{4}{|c|}{ Week } \\
\hline & & 1 & 2 & 3 & 4 \\
\hline \multirow[t]{8}{*}{ TS1 } & Squat & Intensity & Intensity & Intensity & Intensity \\
\hline & Lounges & $70 \%-1 \mathrm{RM}$ & $70 \%-1 \mathrm{RM}$ & $70 \%-1 \mathrm{RM}$ & 70\%-1RM \\
\hline & Bench press & Reps: 10-12 & Reps: 10-12 & Reps: 10-12 & Reps: 10-12 \\
\hline & Rowing & Sets: 2 & Sets: 2 & Sets: 3 & Sets: 3 \\
\hline & & Rest: $60 \mathrm{sec}$ & Rest: $60 \mathrm{sec}$ & Rest: $90 \mathrm{sec}$ & Rest: $90 \mathrm{sec}$ \\
\hline & Abdominals & Reps: 20 & Reps: 20 & Reps: 20 & Reps: 20 \\
\hline & Low back & Sets: 3 & Sets: 3 & Sets: 4 & Sets: 4 \\
\hline & & Rest: $60 \mathrm{sec}$ & Rest: $60 \mathrm{sec}$ & Rest: $60 \mathrm{sec}$ & Rest: $60 \mathrm{sec}$ \\
\hline \multirow[t]{5}{*}{ TS2 } & Running & Intensity & Intensity & Intensity & Intensity \\
\hline & & 75\%-MHR & 75\%-MHR & 80\%-MHR & 80\%-MHR \\
\hline & Abdominals & Reps: 20 & Reps: 20 & Reps: 20 & Reps: 20 \\
\hline & Low back & Sets: 3 & Sets: 3 & Sets: 4 & Sets: 4 \\
\hline & & Rest: $60 \mathrm{sec}$ & Rest: $60 \mathrm{sec}$ & Rest: $60 \mathrm{sec}$ & Rest: $60 \mathrm{sec}$ \\
\hline \multirow[t]{8}{*}{ TS3 } & Squat & Intensity & Intensity & Intensity & Intensity \\
\hline & Lounges & $70 \%$ & $70 \%$ & $70 \%$ & $70 \%$ \\
\hline & Bench Press & Reps: 10-12 & Reps: 10-12 & Reps: 10-12 & Reps: 10-12 \\
\hline & Rowing & Sets: 2 & Sets: 2 & Sets: 3 & Sets: 2 \\
\hline & & Rest: $60 \mathrm{sec}$ & Rest: $60 \mathrm{sec}$ & Rest: $90 \mathrm{sec}$ & Rest: $90 \mathrm{sec}$ \\
\hline & Abdominals & Reps: 20 & Reps: 20 & Reps: 20 & Reps: 20 \\
\hline & Low back & Sets: 3 & Sets: 3 & Sets: 4 & Sets: 4 \\
\hline & & Rest: $60 \mathrm{sec}$ & Rest: $60 \mathrm{sec}$ & Rest: $60 \mathrm{sec}$ & Rest: $60 \mathrm{sec}$ \\
\hline \multirow[t]{8}{*}{ TS4 } & High intensity Running & Intensity & Intensity & Intensity & Intensity \\
\hline & & 87\%-95\%-MHR & 87\%-95\%-MHR & 87\%-95\%-MHR & 87\%-95\%-MHR \\
\hline & & Duration: 3 min & Duration: 3 min & Duration: 4 min & Duration: 4 min \\
\hline & & Sets: 3 & Sets: 3 & Sets: 3 & Sets: 3 \\
\hline & & Rest: 4 min & Rest: 4 min & Rest: 4 min & Rest: 4 min \\
\hline & Abdominals & Reps: 20 & Reps: 20 & Reps: 20 & Reps: 20 \\
\hline & Low back & Sets: 3 & Sets: 3 & Sets: 4 & Sets: 4 \\
\hline & & Rest: $60 \mathrm{sec}$ & Rest: $60 \mathrm{sec}$ & Rest: $60 \mathrm{sec}$ & Rest: $60 \mathrm{sec}$ \\
\hline
\end{tabular}

TS 1, first training session of the week—strength training in gym; TS 2, second training session of the week—aerobic training in soccer pitch; TS 3, third training session of the week — strength training in gym; TS 4, fourth training session of the week—aerobic high intensity running training in soccer pitch; 1RM, one-repetition maximum; MHR, maximum heart rate; Reps, repetitions. 
days. Usually, youth players during the recovery/holiday period do not perform any kind of training program and when the preseason period begins, the trainers try to gain all the physical condition elements that have been reduced from the cessation of training.

Therefore, the purpose of this study was to determine whether the 8 weeks of the off-season period divided in the first part of recovery for 4 weeks and then followed by a period of training for 4 weeks can influence strength performance in the lower limbs in youth soccer players. The program of the training period included exercises for aerobic capacity and maximal strength.

\section{MATERIALS AND METHODS}

\section{Design}

The study was conducted in 8 weeks within the off-season period. One week after the end of the competitive season the subjects participated in baseline tests (anthropometric and strength assessment). The following 4 weeks made up the recovery period (detraining period), which the players did not participate in any kind of training. For the next 4 weeks, they performed a training program which included exercises for aerobic capacity and maximal strength. The characteristics of the training program presented in Table 1. Anthropometric and strength tests were performed after the recovery period ( 4 weeks) to evaluate the influence of detraining and after the training period ( 4 weeks) to evaluate the influence of the program. All the tests were performed at the same time and under the same conditions and subjects were instructed to follow their usual daily diet pattern throughout the study. Warm-up was the same for all training sessions.

\section{Subjects}

Thirteen elite youth male soccer players volunteered to participate in the study. All players were members of an academy of a professional soccer club. Experimental procedures and potential risks, discomforts, and benefits were fully explained to all boys and parents/guardians prior to participation. Signed informative consent forms were provided by subjects' parents and/or legal guardians. All the procedures were in accordance with the Declaration of Helsinki. Subjects' characteristics are shown in Table 2 .

\section{Anthropometrics}

Body mass was measured to the nearest $0.1 \mathrm{~kg}$ using an electronic digital scale with the participants wearing their under-
Table 2. Subjects' physical characteristics

\begin{tabular}{lrcc}
\hline Variable & Pre detraining & After detraining & Post strength training \\
\hline Age $(\mathrm{yr})$ & $15.1 \pm 0.3$ & $15.2 \pm 0.3$ & $15.3 \pm 0.3$ \\
Height $(\mathrm{cm})$ & $167.8 \pm 8.5$ & $168.7 \pm 8.5$ & $169.6 \pm 8.7$ \\
Weight $(\mathrm{kg})$ & $59.4 \pm 2.5$ & $60.2 \pm 2.7$ & $60.5 \pm 1.7$ \\
Body fat $(\%)$ & $14.6 \pm 2.3$ & $14.7 \pm 2.5$ & $14.4 \pm 2.5$
\end{tabular}

Values are presented as mean \pm standard deviation.

clothes and barefoot. Standing height was measured to the nearest $0.1 \mathrm{~cm}$ (Seca 220e, Hamburg, Germany). Body fat percentage was estimated based on the sum of four (biceps, triceps, suprailiac, subscapular) skinfold thicknesses measured with a specific caliper (Lafayette Insurance LLC, Lafayette, IN, USA) on the right side of the body as described by (Slaughter et al., 1988). Estimation of the body density was calculated according to the Durnin and Rahaman (1967) equation for male youth (younger than age 16 years), and estimated by the equation of Siri (1956).

\section{Isokinetic strength}

The strength of knee flexors and extensors in both legs was measured using an isokinetic dynamometer (CSMI, Humac Norm Testing \& Rehabilitation System, Stoughton, MA, USA). Prior to each testing session, subjects performed a 10-min warm-up on a cycle ergometer (Monark 839, Vansbro, Sweden). The subjects were then seated on the dynamometer in an adjustable chair. The upper body was stabilized with straps secured diagonally across the chest and the hips. Maximal isokinetic strength was recorded as the torque of the harmstrings (knee flexors, $\mathrm{KF}$ ) and quadriceps (knee extensors, $\mathrm{KE}$ ) muscles at every $5^{\circ}$ throughout the whole range of motion (ROM) at angular velocities of $60 \% \mathrm{sec}, 180^{\circ} / \mathrm{sec}$, and $300 \%$ sec as described (Draganidis et al., 2015). The intraclass correlation coefficients for repeated measures were 0.94 to 0.96 . Lastly, peak torque was measured using a speed controlled isokinetic dynamometer.

\section{Statistical analysis}

Data are presented as mean \pm standard deviation. Data normality was verified with the 1-sample Kolmogorov-Smirnoff test; therefore, a nonparametric test was not necessary. Data was analyzed by a one-way repeated measures analysis of variance. When a significant effect was found, post boc analysis was performed through a Bonferonni test. The level of significance was set at $\alpha=$ 0.05. The SPSS ver. 16.0 (SPSS Inc., Chicago, IL, USA) was used for all analysis. 


\section{RESULTS}

\section{Anthropometric}

No changes were noted in the measurements concerning all the anthropometric variables $(P>0.05)$. The anthropometric characteristics of the two measurements are presented in Table 2.

\section{Isokinetic strength}

No changes were noted in isokinetic strength measures of $\mathrm{KF}$ and $\mathrm{KE}$ of both limbs at all velocities $60^{\circ} \mathrm{sec}, 180^{\circ} / \mathrm{sec}$, and $300^{\circ} \%$ $\sec (P>0.05)$ (Figs. 1, 2). The ratio of $\mathrm{KF} / \mathrm{KE}$ (Fig. 3) remained unchanged in all the measurements $(P>0.05)$.

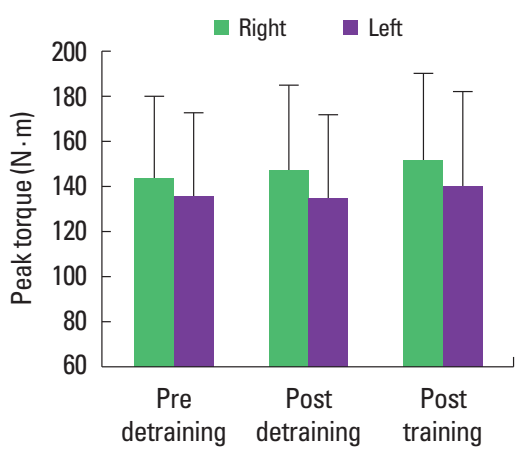

Knee flexors $(60 \% \mathrm{sec})$

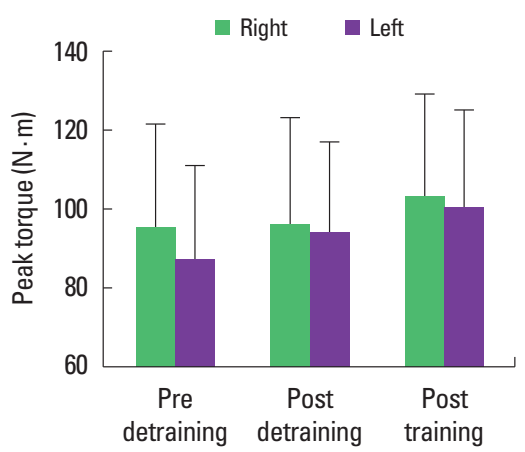

Knee flexors $(180 \% \mathrm{sec})$

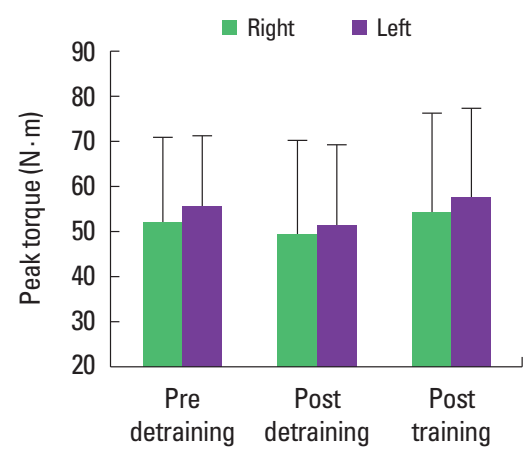

Knee flexors $\left(300^{\circ} / \mathrm{sec}\right)$

Fig. 1. Changes in isokinetic peak torque of knee flexors at $60 \% \mathrm{sec}, 180^{\circ} / \mathrm{sec}$, and $300 \% \mathrm{sec}$ before and after detraining period and after strength training.

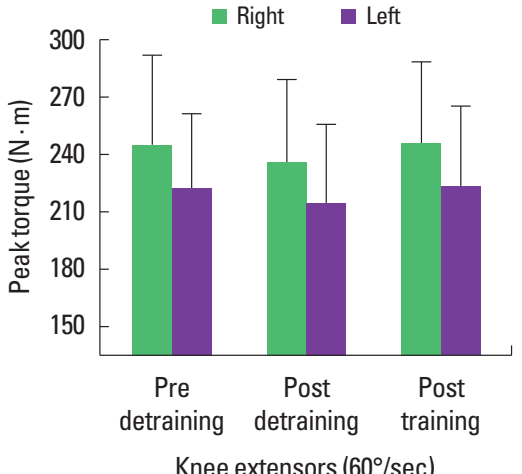

Knee extensors $(60 \% \mathrm{sec})$

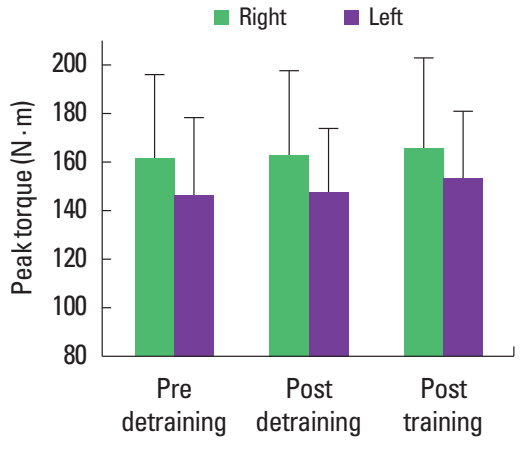

Knee extensors $(180 \% \mathrm{sec})$

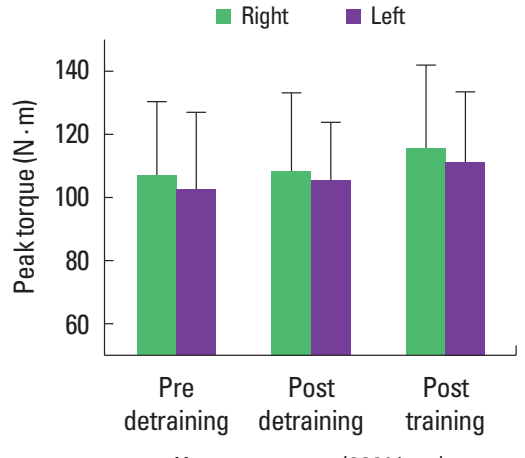

Knee extensors $(300 \% \mathrm{sec})$

Fig. 2. Changes in isokinetic peak torque of knee extensors at $60^{\circ} / \mathrm{sec}, 180 \% \mathrm{sec}$, and $300 \% \mathrm{sec}$ before and after detraining period and after strength training.
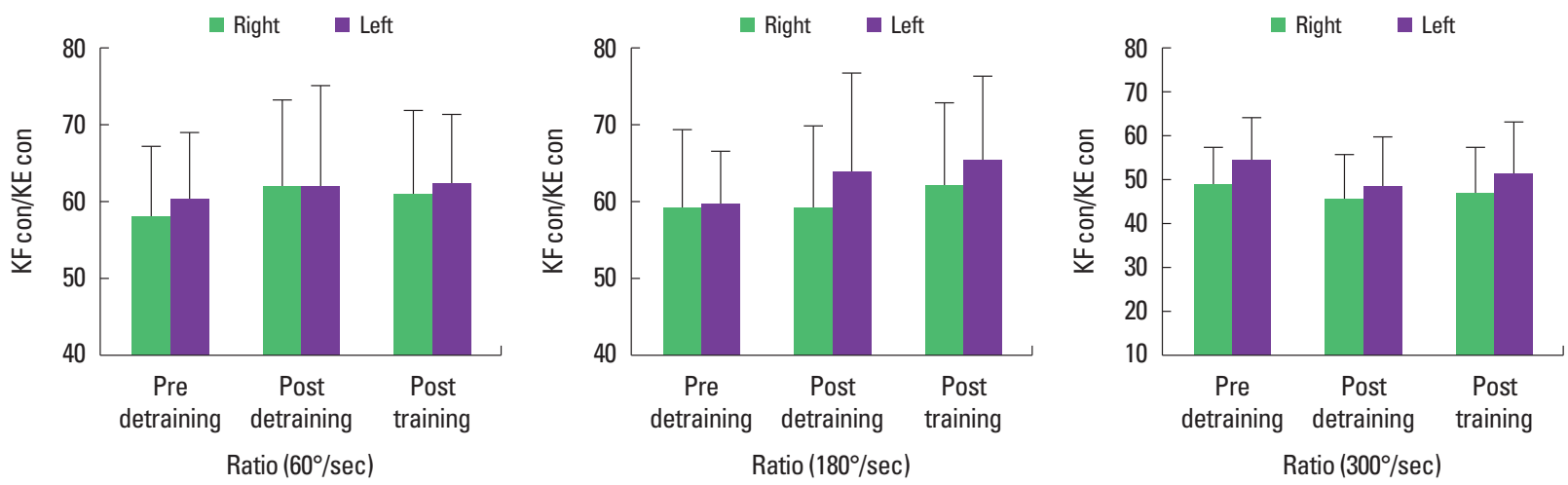

Fig. 3. Changes in ratios of knee flexors (KFs) and knee extensors (KEs) at $60 \% / \mathrm{sec}, 180 \% \mathrm{sec}$, and $300 \%$ sec before and after detraining period and after strength training. 


\section{DISCUSSION}

The major finding in the present study was that 4 weeks of detraining in elite youth soccer players does not have any significant effects according to their anthropometric characteristics and isokinetic strength of their lower limbs. This observation can help trainers to plan off season individual programs for elite youth players. In accordance with the above findings the absence of strength training in their training programs could not affect their isokinetic strength. However, this age of boys is crucial for strength development and as mentioned above this period (recovery/holiday period) could be very useful for athletic development. Furthermore, trainers have to think if elite youth soccer players must abstain from strength training.

In our study, we observed that after a 4-week recovery period (detraining) the body mass increased and also increased the percentage of body fat. However, these increments were not significant and similar results mentioned from recent studies (Chatzinikolaou et al., 2018; Joo, 2018). In other studies we can observe different influences in the anthropometric variables. More specifically, in professional and semiprofessional soccer players mentioned trivial to small increases of body fat (Caldwell and Peters, 2009; Koundourakis et al., 2014; Ostojic, 2003; Reinke et al., 2009; Sotiropoulos et al., 2009). In other study, in professionals, large decrements in fat free mass were observed (D'Ascenzi et al., 2015). All of the above studies were performed to adult soccer players in contrast with our study that the participants were pubertal boys.

However, in the present study, the percentage of body fat decreased after the training program and reached a lower level in comparison with the first measure but the changes were not significant. In another study (Sotiropoulos et al., 2009) that used an off-season general training program observed that the training group had smaller increases in body mass and in the percentage of body fat.

In this study the effect of 4 weeks detraining in neuromuscular factors and more precisely in strength were not significant. Similar results found from other researchers that mentioned that 1,2 , 3 , and 4 weeks without training did not significantly reduce the isokinetic concentric knee flexion and extension force and lower limb isometric strength (Chaouachi et al., 2018; Joo, 2016, 2018; Lehnert et al., 2014; Mujika and Padilla, 2000a). In contrast, in a recent study (Chatzinikolaou et al., 2018) mentioned that 5 weeks of off-season detraining induced a deterioration of $\mathrm{KE}$ and $\mathrm{KF}$ strength at low speed movements and in high speed movements the greater reduction observed on eccentric strength of $\mathrm{KF}$ and concentric strength of KE. Previous studies mentioned that detraining effects on performance are related to factors such as maturation, training level and total training load before the detraining (Faigenbaum et al., 2009) and these may be the reasons for the differences in results between the studies.

The training program that was performed in the present study did not improve the lower limb strength. In contrast, other studies (Chatzinikolaou et al., 2018) mentioned that the influence of a 5 -week training program not only attenuated the decline of strength performance but also enhanced it in soccer players.

In the present study, the ratios of peak torques of $\mathrm{KF}$ and $\mathrm{KE}$ was unchanged after the detraining period and after the training program but remained within their physiological range indicating a reduced risk for hamstrings' injury (Draganidis et al., 2015). These results were similar with those mentioned by other researchers (Chatzinikolaou et al., 2018).

A lot of studies mentioned that youth can maintain training benefits from baseline to detraining period (Faigenbaum et al., 1996; Faigenbaum et al., 2013; Granacher et al., 2011; Santos et al., 2011; Santos et al., 2012) better than adults, as a result of a more malleable growth maturation and neuromuscular physiology (Behm et al., 2008). Furthermore, is suggested that neural adaptations play a significant role in youth strength training adaptations (Behm et al., 2008; Faigenbaum et al., 1996; Faigenbaum et al., 2009). Additionally, if the youth are active, not with specific resistance exercises, this could be sufficient stimulus to maintain the training adaptations (Chaouachi et al., 2018). All of the above factors may be the reasons for the lack of strength detraining in our study.

In the present study, a muscle hypertrophy strength program was performed which did not influence the isokinetic lower limb strength of the participants. Perhaps, the duration of the program is the reason for the lack of training adaptations. The total of 8 strength trainings was not enough to improve the strength performance in elite youth soccer players.

In conclusion, this study showed that 4 weeks of detraining in elite youth soccer players did not significantly affect their strength performance of the lower limb and their anthropometric characteristics. Additionally, a 4-week training program, with 2 strength trainings per week in the $70 \%$ of the one-repetition maximum did not affect the strength performance and anthropometric characteristics significantly. 


\section{CONFLICT OF INTEREST}

No potential conflict of interest relevant to this article was reported.

\section{REFERENCES}

Behm DG, Faigenbaum AD, Falk B, Klentrou P. Canadian Society for Exercise Physiology position paper: resistance training in children and adolescents. Appl Physiol Nutr Metab 2008;33:547-561.

Caldwell BP, Peters DM. Seasonal variation in physiological fitness of a semiprofessional soccer team. J Strength Cond Res 2009;23:1370-1377.

Chaouachi A, Ben Othman A, Makhlouf I, Young JD, Granacher U, Behm DG. Global training effects of trained and untrained muscles with youth can be maintained during 4 weeks of detraining. J Strength Cond Res 2018 May 23 [Epub]. https://doi.org/10.1519/JSC.0000000000002606.

Chatzinikolaou A, Michaloglou K, Avloniti A, Leontsini D, Deli CK, Vlachopoulos D, Gracia-Marco L, Arsenis S, Athanailidis I, Draganidis D, Jamurtas AZ, Williams CA, Fatouros IG. The trainability of adolescent soccer players to brief periodized complex training. Int J Sports Physiol Perform 2018;13:645-655.

D’Ascenzi F, Pelliccia A, Cameli M, Lisi M, Natali BM, Focardi M, Giorgi A, D’Urbano G, Causarano A, Bonifazi M, Mondillo S. Dynamic changes in left ventricular mass and in fat-free mass in top-level athletes during the competitive season. Eur J Prev Cardiol 2015;22:127-134.

Draganidis D, Chatzinikolaou A, Avloniti A, Barbero-Álvarez JC, Mohr M, Malliou P, Gourgoulis V, Deli CK4, Douroudos II, Margonis K, Gioftsidou A, Flouris AD, Jamurtas AZ, Koutedakis Y, Fatouros IG. Recovery kinetics of knee flexor and extensor strength after a football match. PLoS One 2015;10:e0128072.

Durnin JV, Rahaman MM. The assessment of the amount of fat in the human body from measurements of skinfold thickness. Br J Nutr 1967; 21:681-689.

Faigenbaum AD, Farrell AC, Fabiano M, Radler TA, Naclerio F, Ratamess NA, Kang J, Myer GD. Effects of detraining on fitness performance in 7-year-old children. J Strength Cond Res 2013;27:323-330.

Faigenbaum AD, Kraemer WJ, Blimkie CJ, Jeffreys I, Micheli LJ, Nitka M, Rowland TW. Youth resistance training: updated position statement paper from the national strength and conditioning association. J Strength Cond Res 2009;23(5 Suppl):S60-79.

Faigenbaum AD, Westcott WL, Michelli LJ, Outerbridge AR, Long CJ, LaRosa-Loud R, Zaichkowsky LD. The effects of strength training and detraining on children. J Strength Cond Res 1996;10:109-114.

Fathi A, Hammami R, Moran J, Borii R, Sahli S, Rebai H. Effect of a 16 week combined strength and plyometric training program followed by a detraining period on athletic performance in pubertal volleyball players. J Strength Cond Res 2018 Feb 1 [Epub]. https://doi.org/10.1519/ JSC.0000000000002461.

Granacher U, Muehlbauer T, Doerflinger B, Strohmeier R, Gollhofer A. Promoting strength and balance in adolescents during physical education: effects of a short-term resistance training. J Strength Cond Res 2011;25:940-949.

Ingle L, Sleap M, Tolfrey K. The effect of a complex training and detraining programme on selected strength and power variables in early pubertal boys. J Sports Sci 2006;24:987-997.

Joo $\mathrm{CH}$. The effects of short term detraining and retraining on physical fitness in elite soccer players. PLoS One 2018;13:e0196212.

Joo $\mathrm{CH}$. The effects of short-term detraining on exercise performance in soccer players. J Exerc Rehabil 2016;12:54-59.

Koundourakis NE, Androulakis NE, Malliaraki N, Tsatsanis C, Venihaki M, Margioris AN. Discrepancy between exercise performance, body composition, and sex steroid response after a six-week detraining period in professional soccer players. PLoS One 2014;9:e87803.

Lehnert M, Psotta R, Chvojka P, Ste Croix MD. Seasonal variation in isokinetic peak torque in youth soccer players. Kinesiology 2014;46:79-87.

Meylan CM, Cronin JB, Oliver JL, Hopkins WG, Contreras B. The effect of maturation on adaptations to strength training and detraining in 1115-year-olds. Scand J Med Sci Sports 2014;24:e156-164.

Mujika I, Padilla S. Detraining: loss of training-induced physiological and performance adaptations. Part I: short term insufficient training stimulus. Sports Med 2000a;30:79-87.

Mujika I, Padilla S. Detraining: loss of training-induced physiological and performance adaptations. Part II: Long term insufficient training stimulus. Sports Med 2000b;30:145-154.

Ostojic SM. Seasonal alterations in body composition and sprint performance of elite soccer players. J Exerc Physiol Online 2003;6:24-27.

Reilly T, Ekblom B. The use of recovery methods post-exercise. J Sports Sci 2005;23:619-627.

Reinke S, Karhausen T, Doehner W, Taylor W, Hottenrott K, Duda GN, Reinke P, Volk HD, Anker SD. The influence of recovery and training phases on body composition, peripheral vascular function and immune system of professional soccer players. PLoS One 2009;4:e4910.

Santos A, Marinho DA, Costa AM, Izquierdo M, Marques MC. The effects of concurrent resistance and endurance training follow a specific detraining cycle in young school girls. J Hum Kinet 2011;29A:93-103.

Santos AP, Marinho DA, Costa AM, Izquierdo M, Marques MC. The effects of concurrent resistance and endurance training follow a detraining period in elementary school students. J Strength Cond Res 2012; 26:1708-1716. 
Silva JR, Brito J, Akenhead R, Nassis GP. The transition period in soccer: a window of opportunity. Sports Med 2016;46:305-313.

Siri WE. The gross composition of the body. Adv Biol Med Phys 1956;4: 239-280.

Slaughter MH, Lohman TG, Boileau RA, Horswill CA, Stillman RJ, Van Loan MD, Bemben DA. Skinfold equations for estimation of body fatness in children and youth. Hum Biol 1988;60:709-723.

Sotiropoulos A, Travlos AK, Gissis I, Souglis AG, Grezios A. The effect of a 4-week training regimen on body fat and aerobic capacity of professional soccer players during the transition period. J Strength Cond Res 2009;23:1697-1703.

Staron RS, Hagerman FC, Hikida RS. The effects of detraining on an elite power lifter. A case study. J Neurol Sci 1981;51:247-257.

Thorstensson A. Observations on strength training and detraining. Acta Physiol Scand 1977;100:491-493. 